\title{
Comorbidities in interstitial lung diseases
}

\author{
George A. Margaritopoulos ${ }^{1}$, Katerina M. Antoniou ${ }^{2}$ and Athol U. Wells ${ }^{1}$ \\ Affiliations: ${ }^{1}$ Interstitial Lung Disease Unit, Royal Brompton Hospital, London, UK. ${ }^{2}$ Interstitial Lung Disease \\ Unit, University Hospital of Heraklion, Heraklion, Greece.
}

Correspondence: Athol U. Wells, Interstitial Lung Disease Unit, Royal Brompton Hospital, London, SW3 6LP, UK. E-mail: RBHILDQrbht.nhs.uk

@ERSpublications

Early detection and accurate management of comorbidity have benefits in reducing ILD morbidity and mortality http://ow.ly/4nmYie

Cite this article as: Margaritopoulos GA, Antoniou KM, Wells AU. Comorbidities in interstitial lung diseases. Eur Respir Rev 2017; 26: 160027 [https://doi.org/10.1183/16000617.0027-2016].

ABSTRACT Fibrosing lung disorders include a large number of diseases with diverse behaviour. Patients can die because of the progression of their illness, remain stable or even improve after appropriate treatment has been instituted. Comorbidities, such as acute and chronic infection, gastro-oesophageal reflux, pulmonary hypertension, lung cancer, cardiovascular diseases, and obstructive sleep apnoea, can pre-exist or develop at any time during the course of the disease and, if unidentified and untreated, may impair quality of life, impact upon the respiratory status of the patients, and ultimately lead to disease progression and death. Therefore, early identification and accurate treatment of comorbidities is essential.

\section{Introduction}

In interstitial lung disease (ILD), recent treatment advances have led to more purposeful management and an expectation of better outcomes than in historical cohorts. This applies equally to the advent of antifibrotic therapies in idiopathic pulmonary fibrosis (IPF) and to the nuanced use of immunosuppressive agents in most other ILDs, in which immune dysregulation is a unifying feature. However, treatment benefits seen in pharmaceutical trials are not always applicable to the general ILD population. The most influential selection bias in pharmaceutical cohorts is probably the exclusion of patients with significant comorbidities, including cardiac disease, malignancy and pulmonary hypertension (PH). In IPF treatment trials, it transpired that mortality observed in placebo arms (approximating 10\% per year) was substantially lower than had been expected, based on published outcomes in IPF clinical series in which the full impact of comorbid disease processes had been captured. Thus, in a large patient subgroup, optimal outcomes depend as much on the detection and management of major comorbid conditions as on ILD-specific therapies [1]. The number of comorbidities diagnosed in an individual patient has a significant impact on survival [2]. In this review, we describe the most common comorbidities in ILDs (table 1) with particular reference to key issues regarding diagnosis and management (tables 2 and 3 ).

\section{Infections}

\section{General considerations}

In IPF, acute pulmonary infection is second only to acute exacerbation (AE) as a cause of rapid progression [3]. Viruses and bacteria have both been associated with the progression of IPF [4-6]. Moreover, MUC5B

Received: Feb 222016 | Accepted after revision: April 162016

Support statement: This review was supported by the National Institute of Health Research Respiratory Disease Biomedical Research Unit at the Royal Brompton and Harefield NHS Foundation Trust and Imperial College London. Funding information for this article has been deposited with the Open Funder Registry.

Conflict of interest: None declared.

Provenance: Submitted article, peer reviewed.

Copyright OERS 2017. ERR articles are open access and distributed under the terms of the Creative Commons Attribution Non-Commercial Licence 4.0. 
TABLE 1 Comorbidities in interstitial lung diseases

Acute and chronic infections

Gastro-oesophageal reflux

Pulmonary hypertension

Cardiac disease

Pulmonary embolism

Lung cancer

Obstructive sleep apnoea

Depression

polymorphism, which appears to have a role in normal macrophage function and effective mucociliary clearance of bacteria, confers increased risk for development of IPF [7, 8]. Plainly, immunosuppression makes ILD patients more vulnerable to infections. In PANTHER-IPF (Prednisone, Azathioprine, and $N$-Acetylcysteine: a Study That Evaluates Response in Idiopathic Pulmonary Fibrosis), immunosuppression had a deleterious effect leading to an excess of hospitalisations and mortality, and it is not currently recommended in IPF $[9,10]$. The lessons of PANTHER-IPF are equally applicable to ILDs other than IPF, in which immunosuppression is widely used. The danger of major infection increases with age and associated immune senescence. Excessive doses of steroids or immunosuppressive agents may cause more harm than good, leading to recurrent chest infections and, paradoxically, to disease progression. In elderly patients, gentle immunosuppression with a low dose of corticosteroids, with or without an additional second-line agent at a reduced dose, may be more beneficial. In this scenario, prophylactic antibiotic therapy may have dual benefits: the prevention of infection and added immunomodulation. Azithromycin, an antibiotic with known immunomodulatory properties, first documented in the successful treatment of pan-bronchiolitis, decreases the prevalence of infective exacerbations in bronchiectasis and other chronic lung diseases, and has a beneficial effect on pulmonary fibrosis in a bleomycin lung model [11-14]. Although no controlled randomised data exists to endorse the routine use of azithromycin in ILDs, it appears logical to consider the prophylactic use of azithromycin in patients experiencing recurrent respiratory infections, with awareness of possible side-effects including reduced hearing acuity and QTc interval prolongation. In support of the long-term use of antibiotics, a recent randomised placebo-controlled trial of co-trimoxazole in fibrotic ILD showed a survival benefit in treatment-adherent patients, perhaps due to antimicrobial activity leading to a reduced rate of infections [15]. Hydroxychloroquine, a historical antibiotic used primarily to treat malaria, is widely used in pulmonary sarcoidosis for its immunomodulatory effects and may also add value in other ILDs when additional gentle immunomodulation is likely to be beneficial. Based on these considerations, it has been proposed that in IPF, a combination of an antifibrotic drug and antibiotic therapy merits formal evaluation [16].

\section{Acute infection}

As acute respiratory infection can cause rapid deterioration of an underlying ILD, a policy of early, broad-spectrum antibiotic therapy for acute infection appears logical. This approach requires patients to have a home supply of antibiotics and to initiate treatment at the first symptomatic management of a lower respiratory tract infection. Acute infection may cause diffuse alveolar damage (DAD) in IPF with a clinical picture and outcome identical to that of AE of IPF (AEIPF), in which, by definition, overt

TABLE 2 Key diagnostic and management issues with regard to comorbidities in interstitial lung diseases (ILDs)

The use of immediate antibiotic treatment for acute respiratory infections

The recognition of chronic infection as a cause of rapid deterioration of ILD

The recognition of GORD as a possible cause of the development and acute deterioration of pulmonary fibrosis

The recognition of disproportionate $\mathrm{PH}$ in patients with mild-to-moderate ILD

The stratification of patients with ILD and lung cancer according to the risk of post-operative complications

The recognition of PE and CAD as causes of shortness of breath that is disproportionate to the extent of the underlying ILD

The diagnosis of OSA and the institution of management associated with good patient compliance. The referral of patients with clinically significant depression for psychiatric advice

GORD: gastro-oesophageal reflux disease; PH: pulmonary hypertension; PE: pulmonary embolism; CAD: coronary artery disease; OSA: obstructive sleep apnoea. 


\begin{tabular}{|c|c|c|}
\hline Comorbidity & Prevalence & Treatment \\
\hline \multirow[t]{4}{*}{ Infections } & NA & Broad-spectrum antibiotics \\
\hline & & Adjust immunosuppression \\
\hline & & $\begin{array}{l}\text { Prophylactic antibiotics in case of recurrent } \\
\text { infections }\end{array}$ \\
\hline & & Specific therapy for chronic infections \\
\hline \multirow{2}{*}{$\begin{array}{l}\text { Gastro-oesophageal } \\
\text { reflux }\end{array}$} & $0-94 \%$ in IPF & Lifestyle changes \\
\hline & & $\begin{array}{c}\text { PPIs, } \mathrm{H}_{2} \text {-receptor antagonists, prokinetics } \\
\text { Fundoplication }\end{array}$ \\
\hline \multirow{3}{*}{$\begin{array}{l}\text { Pulmonary } \\
\text { hypertension }\end{array}$} & $32-85 \%$ in IPF, $5-74 \%$ in & Treatment of contributing factors \\
\hline & $\begin{array}{l}\text { sarcoidosis and } 5-12 \% \text { in } \\
\text { SSc }\end{array}$ & $\begin{array}{l}\text { Anti-pulmonary hypertension treatment is not } \\
\text { recommended in IPF but combination of antifibrotic } \\
\text { agents with targeted therapy for pulmonary } \\
\text { hypertension may be considered }\end{array}$ \\
\hline & & $\begin{array}{l}\text { Combination of immunosuppression and } \\
\text { anti-pulmonary hypertension agents in SSC-ILD }\end{array}$ \\
\hline \multirow[t]{4}{*}{ Cardiac disease } & $60 \%$ in IPF, $20 \%$ in & Immunosuppression when necessary \\
\hline & sarcoidosis & $\begin{array}{c}\text { Specific pharmacological treatment for cardiac } \\
\text { disease }\end{array}$ \\
\hline & & ICD implantation (mainly in sarcoidosis) \\
\hline & & Consider the likelihood of drug-induced ILD \\
\hline Pulmonary embolism & NA & Anticoagulation (avoid vit-K antagonists in IPF) \\
\hline Lung cancer & $4.4-10 \%$ in IPF & $\begin{array}{l}\text { Radiotherapy, chemotherapy, surgical removal } \\
\text { Careful pre-operative assessment }\end{array}$ \\
\hline \multirow{2}{*}{$\begin{array}{l}\text { Obstructive sleep } \\
\text { apnoea }\end{array}$} & $60-90 \%$ in IPF, $50 \%$ in & CPAP machine \\
\hline & $\begin{array}{l}\text { SSc-ILD, } 65 \% \text { in } \\
\text { sarcoidosis }\end{array}$ & Follow-up to check compliance/adherence \\
\hline Depression & $\begin{array}{l}>20 \% \text { in ILDs, } 11-50 \% \text { in } \\
\text { IPF }\end{array}$ & $\begin{array}{l}\text { The role of antidepressants is under debate } \\
\text { Pulmonary rehabilitation }\end{array}$ \\
\hline
\end{tabular}

NA: not applicable; IPF: idiopathic pulmonary fibrosis; PPI; proton-pump inhibitor; SSc: systemic sclerosis; ICD: implantable cardioverter-defibrillator; vit-K: vitamin K; CPAP: continuous positive airway pressure.

infection is not present [17], and may be a frequent occult trigger of AEIPF [18, 19]. There is a higher incidence of AEIPF during winter and spring months, coinciding with a higher prevalence of acute infection [20, 21]. In most AEIPF cases, there is a history of increasing dyspnoea over several weeks: it appears likely that infections triggering the onset of AEIPF will not be detected by the time the patient comes to medical attention. Indeed, it can be argued that DAD associated with proven infection in IPF should be included as a subtype of AEIPF $[18,19,22]$. Patients with IPF and DAD in association with infection do not differ in pulmonary function tests, high-resolution computed tomography (HRCT) findings, bronchoalveolar lavage (BAL) differential cell counts or mortality when compared to patients with AEIPF [23]. This observation is important as the use of BAL to diagnose infection in apparent AEIPF adds to risk in patients with already impaired lung function and may not add useful information in terms of treatment (as empirical antibiotic therapy is widely used in AEIPF).

By contrast, in ILDs other than IPF, and especially in connective tissue disease (CTD)-associated ILDs, in which immunosuppressive therapy is the cornerstone of management, the distinction between exacerbations of ILD and either acute or opportunistic infection has major management implications. For instance, acute-onset diffuse ILD in patients with rheumatoid arthritis on treatment with biological agents is commonly due to Pneumocystis jirovecii infection [24]. The dilemma for the clinician is whether to increase or decrease the level of immunosuppression and institute intensive treatment for infection, tailored to cultured microorganisms. In this scenario, BAL is a pivotal test [25]. In severely compromised patients, admission to an intensive care unit should be considered in order to perform BAL with ready access to mechanical ventilation.

\section{Challenges in chronic infection}

Patients with fibrotic ILDs are susceptible to chronic pulmonary infections, mainly from Mycobacterium and Aspergillus species, which often simulate traditional disease progression at both a clinical and imaging level, and pre-existing fibrotic changes may mask typical imaging appearances of infection [26, 27]. Chronic pulmonary aspergillosis occurs more frequently in sarcoidosis than in other ILDs [26]. The long-term use of steroids or other immunosuppressive drugs are predisposing factors. Initially, treatment 
includes the use of intravenous voriconazole followed by oral voriconazole or itraconazole [28, 29]. Intravenous caspofungin could be used as salvage therapy in cases refractory to standard therapy or when first-line agents are poorly tolerated and can stabilise previously progressive pulmonary fungal disease, as judged by lung function, HRCT imaging and symptoms [30].

Another challenge is to distinguish between latent or active tuberculosis and sarcoidosis, and especially to make a diagnosis of coexistent tuberculosis in sarcoidosis. The tuberculin skin test is more likely to provide false-negative results in active sarcoidosis due to cutaneous anergy to tuberculin. Therefore, the use of interferon- $\gamma$ release assays (IGRAs) is more sensitive in the detection of latent tuberculosis infection in sarcoidosis and if positive, is indicative of latent tuberculosis, requiring consideration of isoniazid prophylaxis [31]. With regard to coexistent sarcoidosis and active tuberculosis, there are particular concerns about tuberculosis reactivation after treatment with steroids or tumour necrosis factor- $\alpha$ inhibitors, especially in countries with a high prevalence of latent infection. The diagnosis of active tuberculosis in sarcoidosis requires the presence of Mycobacterium tuberculosis in smear exam or culture. However, given the overlap in clinical features between active tuberculosis and sarcoidosis, empirical treatment for active tuberculosis may be appropriate, after multidisciplinary discussion, in culture-negative sarcoidosis patients with tuberculin skin test positivity, especially when disease is resistant to sarcoidosis specific therapy and an IGRA test is positive.

In sarcoidosis patients with recurrent upper and lower tract respiratory infections, the likelihood of an underlying immunodeficiency should be explored. In granulomatous disorders initially diagnosed as sarcoidosis, the diagnosis of common variable immune deficiency (CVID) should be considered when there is coexisting hypogammaglobulinaemia. CVID is associated with a sarcoid-like disease in the lungs and predispose to recurrent bacterial infections [32]. Granulomatous and lymphocytic interstitial lung disease (GLILD) is the most common lung complication of CVID. It differs from sarcoidosis in many aspects. The most frequent HRCT pattern in GLILD is infiltration by large nodules that are more profuse in the lower zones but are otherwise randomly distributed, whereas in sarcoidosis, micronodular HRCT abnormalities are perilymphatic and occur mostly in the upper zones. Free-standing bronchiectasis (i.e. nontraction bronchiectasis) is more commonly seen in CVID. GLILD rarely regresses spontaneously and has a worse prognosis than sarcoidosis [33].

\section{Gastro-oesophageal reflux}

The strong association between gastro-oesophageal reflux (GOR) and lung fibrosis has mostly been studied in IPF [34]. The reported prevalence of GOR in IPF has varied from $0 \%$ to $94 \%$ [35], with, in larger series, the prevalence of distal and proximal GOR varying from $67 \%$ to $88 \%$ and from $30 \%$ to $74 \%$, respectively [36-40]. GOR is an important comorbidity in IPF because it has implications both for patient quality of life and, more contentiously, for IPF pathogenesis.

\section{Symptomatic GOR}

Potential quality of life benefits justify antacid therapy for symptomatic GOR, especially in patients with major sleep disturbance due to episodes of waking with a choking sensation. Treatment includes lifestyle changes such as small frequent meals, elevating the head of the bed on blocks, avoidance of lying supine for 3-4 h after eating, avoidance of garlic, onions, heavily spiced food, excessive tea, coffee or alcohol. Laparoscopic fundoplication may be required for severe symptomatic reflux resistant to high dosage protein pump inhibitors, $\mathrm{H}_{2}$-receptor antagonists and prokinetic agents.

\section{The pathogenetic significance of GOR}

The pathogenetic role of GOR in IPF (and in other ILDs) is uncertain. It is sometimes argued that GOR in ILD is entirely a secondary phenomenon associated with progressive pulmonary fibrosis because of increased negative intrathoracic pressure due to lung restriction, leading to distortion of mediastinal structures and traction on the oesophagus, weakening of the lower oesophageal sphincter and subsequent microaspiration of gastric refluxate. The current consensus, in the absence, it should be stressed, of definitive data, is that GOR is likely to be pathogenetic in some cases, providing a profibrotic stimulus due to repetitive damage of the alveolar epithelium with recurrent microaspiration. If this view is correct and GOR is a key initial fibrogenetic trigger in some patients with ILD, the development of more severe GOR in advanced disease (as a secondary phenomenon) provides a plausible pathway for accelerated disease progression and, especially, for the higher prevalence of AEIPF in patients with more severe lung restriction.

The case for a pathogenetic role for GOR in ILD arises in part from the unexpected observation that occult GOR is a major risk factor for post-transplantation acute rejection/bronchiolitis obliterans syndrome, raising the possibility that the importance of GOR as a factor inciting progression of lung disease may have been undervalued historically. Patients undergoing fundoplication prior to or shortly after lung 
transplantation have improved survival compared to those not undergoing antireflux surgery [41]. In IPF, recent clinical studies have provided indirect evidence that GOR may provoke disease progression. Initial reports showed stabilisation of IPF with antiacid therapy in a handful of IPF patients [42]. Subsequently, in a study of patients with asymmetric IPF on HRCT, the prevalence of symptomatic GOR was found to be much higher than in patients with symmetric disease. There was a very strong concordance between the distribution of IPF and the usual patient sleeping position, with the more extensive fibrosis in the dependent lung in $94 \%$ of patients. AEIPF occurred much more frequently in asymmetric IPF, with the HRCT features of acute lung injury occurring predominantly in the more involved lung [43]. Pepsin, a nonacid component of gastric juice not normally present in distal airways (and, thus, a marker of aspiration) is more often present in BAL fluid in patients with AEIPF than in those with stable IPF [44].

However, recent retrospective data from pharmaceutical cohorts is more difficult to interpret. In a meta-analysis of the placebo arms in three IPF-net trials, the rate of disease progression (as judged by serial changes in forced vital capacity (FVC)) was significantly lower in patients receiving antiacid therapy than in the remaining cases [45]. By contrast, in an analysis of the placebo arms in three pirfenidone trials, the use of antiacid treatment had no effect on the rate of FVC decline [46]. In a post hoc analysis of the two INPULSIS nintedanib studies, presented at the 2015 European Respiratory Society (ERS) International Congress, the use of concomitant antiacid therapy was actually associated with trends towards a worse outcome [47].

In large IPF clinical cohorts, survival was found to be increased in patients treated medically for GOR or undergoing Nissen fundoplication [48]. It should be emphasised that these retrospective observations have yet to be tested prospectively: at this stage, the efficacy of medical and surgical treatment of GOR in retarding disease progression in IPF remain uncertain. Based on retrospective data, antireflux treatment appears logical in patients with IPF and a hiatus hernia (a common risk factor for GOR) in the hope of reducing the rate of IPF decline in this subgroup [49].

In experimental models, chronic aspiration-related lung injury was independent of $\mathrm{pH}$, implying that nonacid reflux may also be relevant [50]. Prospective studies in ILDs are needed in order to evaluate if nonacid reflux is pathogenetic, justifying the performance of $24-\mathrm{h} \mathrm{pH}$ monitoring and impedence studies. If it is eventually established that asymptomatic GOR may contribute to IPF disease progression, a further dilemma will arise: should all IPF patients be treated with reflux therapy or only those in whom GOR is identified by means of gastroscopy, acid studies or oesophageal manometry?

\section{Should antiacid therapy be instituted routinely in IPF?}

The uncertainties surrounding this question are captured in the recent treatment update of the American Thoracic Society/ERS/Japanese Respiratory Society/Latin American Thoracic Society guidelines [10]. A weak positive treatment recommendation for antiacid therapy was made by the voting panel of "nonconflicted" experts (i.e. a group of experts experienced in data evaluation in various disease settings, with no perceived conflict of interest, i.e. no history of collaboration with pharmaceutical companies in the development of IPF therapies). However, as outlined in an editor's note in the update document, the majority of "conflicted experts" (i.e. leading IPF specialists serving as a knowledge resource in the guideline formulation but not participating in voting) disagreed with the recommendation, which in effect "suggests" the routine use of antiacid agents in IPF. Given this divergence of views, it may be useful to summarise the case for and against.

In favour of routine GOR treatment is the indirect retrospective evidence that GOR might play a pathogenetic role, the inexpensiveness of antiacid therapy and the absence of major side-effects. The recommendation can perhaps be summarised as a view that as 1) IPF remains a lethal disease despite recent treatment advances, 2) symptomatic GOR may have an important pathogenetic role and 3) there is little potential downside to treatment, speculative therapy is warranted in most patients, without the need to confirm occult GOR in individual cases.

Against routine GOR treatment is the fact that it has yet to be established that asymptomatic GOR is truly pathogenetic and the exact prevalence is uncertain. There are also major reservations about the perception that routine GOR therapy poses no significant risk in IPF. Gastric acid makes a significant contribution to antimicrobial defences: the impact of regular antiacid therapy on the composition of the microbiome, recently linked to IPF disease progression [6], is entirely uncertain. In patients with more severe disease (FVC $<70 \%$ of the predicted value), the rate of pulmonary infection was increased in prevalence in those receiving antiacid treatment (although antiacid usage was not associated with greater IPF progression) [46]. Pulmonary microaspirate contains pepsin and bile salts, which may cause lung injury: in asymptomatic patients, suppression of future GOR symptoms might, at least in principle, lead to failure to adopt nonpharmaceutical measures to reduce GOR (diet, change in posture, etc.), leading to increased lung epithelial injury from nonacid reflux. Furthermore, if GOR is not truly pathogenetic, the additional 
medication burden may reduce overall patient adherence, with deleterious effects on the efficacy of other therapies, including antifibrotic agents. Based on uncertain efficacy and the theoretical possibility of major disadvantages, many would share the view that formal prospective trial data are needed before routine GOR treatment can be advocated in IPF patients who may have symptomatic reflux. However, the recent weak positive recommendation reduces the likelihood that the performance of placebo-controlled trials will be achievable.

In systemic sclerosis (SSc), ILD is a major cause of death [51, 52]. There is evidence that epithelial injury makes a contribution to the pathogenesis of lung fibrosis and GOR, a common symptom in SSc, may be implicated [53, 54]. In addition, radiological and histological findings suggestive of GOR-related lung disease were observed in SSc [54]. In the case of idiopathic inflammatory myopathies (IIMs), oesophageal and pharyngeal muscle weakness can also lead to microaspiration and lung injury. Thus, GOR should be actively sought in ILDs other than IPF and treated accordingly.

\section{Pulmonary hypertension \\ Classification}

$\mathrm{PH}$ secondary to a number of individual lung diseases is grouped within a single category in the world $\mathrm{PH}$ classification (group 3) [55]. It is generally accepted that due to differences in PH manifestations between, for example, ILD and chronic obstructive pulmonary disease, and the existence of disease-specific $\mathrm{PH}$ mechanisms in individual ILDs (e.g. sarcoidosis and Langerhans cell histiocytosis), the group $3 \mathrm{PH}$ disorders cannot be amalgamated in the creation of an evidence base to evaluate therapies. However, it is also clear that some form of integration is required. Because IPF is, by far, the most prevalent idiopathic interstitial pneumonia (IIP), PH-IPF tends to be reported in published manuscripts. Other forms of PH-IIP are simply too rare to allow definitive a priori evaluation of $\mathrm{PH}$ therapies. Amongst the IIPs, including IPF, the unifying $\mathrm{PH}$ association observed in clinical practice has been an association between the development of $\mathrm{PH}$ and progression of the underlying lung disease to an extensive fibrotic pattern with the histology of nonspecific interstitial pneumonia (NSIP) or usual interstitial pneumonia (UIP) (the defining histological pattern of IPF).

There are no data to suggest that $\mathrm{PH}$ differs in its mechanisms or clinical manifestations between IPF-PH and NSIP-PH. No differences have been reported in hypoxia-limited exercise intolerance, disproportionate reduction in measures of gas transfer, enlargement of the pulmonary artery on HRCT and echocardiographic findings typical of PH. More importantly, despite major differences in survival between IPF and idiopathic NSIP (due to differences in the progression of interstitial lung disease), in patients with diffusing capacity of the lung for carbon monoxide (DLCO) $<35 \%$ of predicted, the two disorders have an identical high mortality and this is likely to reflect supervening $\mathrm{PH}[56]$.

Thus, a PH classification system in which $\mathrm{PH}$ is viewed as a separate disorder in very individual ILD appears counterintuitive and is bound to result in the effective disenfranchisement of rare ILDs in which definitive placebo-controlled studies are wholly impracticable. The recent acceptance of this view, with the publication of a placebo-controlled trial of bosentan for PH in fibrotic IIP [57], establishes an important precedent. It is now for expert groups to determine whether $\mathrm{PH}$ in chronic hypersensitivity pneumonitis and in CTD-ILD patients with severe ILD (mostly with UIP or fibrotic NSIP as underlying lung histological patterns) might be grouped in a "PH-pulmonary fibrosis" entity for trial purposes, also containing fibrotic IIP including unclassifiable disease.

\section{Prevalence and prognostic significance}

It is strongly recommend that patients with suspected $\mathrm{PH}$, mainly when associated with early disease and when disproportionate to the underlying ILD, should be referred to specialist $\mathrm{PH}$ centres. $\mathrm{PH}$ is considered a predictor of poor survival and an indication for immediate listing for lung transplantation [58]. In patients with advanced IPF assessed for lung transplantation, the presence of PH at baseline is associated with higher risk for the development of AEs and consequent poor survival [59].

The prevalence of $\mathrm{PH}$ varies in ILDs depending on 1) patient selection (most of the studies include patients listed for lung transplantation), 2) time of investigation (the more advanced the disease the higher the prevalence) and 3) measurement technique (right heart catheterisation (RHC) or heart ultrasound). In IPF, the prevalence varies from $32 \%$ to $85 \%$ [60], in sarcoidosis from $5 \%$ to $74 \%$ [61] and in SSc from 5\% to $12 \%$ [62].

\section{Diagnosis}

Physical examination may reveal signs suggestive of PH. It should be stressed that these signs (loud pulmonary component of the second heart sound, right ventricular heave, elevated jugular venous pressure and ankle oedema) are not specific and are frequently present in advanced disease. RHC remains the gold standard diagnostic procedure. Major elevation of pulmonary vascular resistance (PVR) predicts rapid 
mortality and is a marker of end-stage disease [63]. However, RHC is invasive and is not free of risk; therefore, unless targeted $\mathrm{PH}$ therapy is under active consideration, a combination of noninvasive procedures (including lung function tests, resting hypoxia, desaturation during the 6-min walking test (6MWT), echocardiography, brain natriuretic peptide (BNP) levels and HRCT features) is sometimes sufficient to make a working diagnosis of $\mathrm{PH}$.

Lung function tests may reveal a decreased DLCO, transfer coefficient of the lung for carbon monoxide $(K C O)$ (DLCO adjusted for alveolar volume $(V \mathrm{~A})$ ) and arterial oxygen tension, whereas the alveolar-arterial oxygen gradient is widened. In isolated ILDs, DLCO levels are usually $20-25 \%$ lower than volumes. When DLCO is disproportionally reduced and paralleled by a disproportionate reduction of KCO (also known as $D \mathrm{LCO} / \mathrm{VA}), \mathrm{PH}$ should be suspected in the absence of concomitant emphysema. In patients with IIP, baseline KCO and 6-month decline in KCO are both associated with increased early and overall mortality and, in a subgroup of patients with follow-up echocardiography, are associated with the development of $\mathrm{PH}$ [64]. In SSc, an elevated FVC/DLCO ratio (in essence, the inverse of KCO) was found to be an independent predictor for the presence of $\mathrm{PH}$ and is included in the DETECT as an indication for the performance of echocardiography [65]. However, in SSc patients with combined pulmonary fibrosis and emphysema (CPFE), elevation of FVC/DLCO is usual, irrespective of the presence or absence of pulmonary vasculopathy [66]. Use of FVC/DLCO has also been explored in IPF but this variable suffers from measurement variability as three variables must be measured (FVC, KCO and VA) whereas KCO is quantified as a single variable (integrated with VA in the computation of DLCO).

Resting hypoxia is not frequent when the DLCO is $>30 \%$ predicted and, if present, is suggestive of $\mathrm{PH}$. Pulmonary vasculopathy is likely to account for the major increase in mortality in IPF patients with DLCO levels $<40 \%$ predicted [67].

Desaturation $<88 \%$ in the $6 \mathrm{MWT}$ when disproportionate to the extent of the underlying ILD should raise the possibility of PH. Thus, reduced DLCo levels, a requirement for supplemental oxygen, or a poor 6-min walk performance should raise suspicion of PH in IPF [68].

Right ventricular systolic pressure (RVSP) estimated at echocardiography has a reasonably good correlation (i.e. a reasonably high $\mathrm{r}$-value) with systolic pulmonary artery pressure (sPAP) at RHC, but it must be understood that echocardiography systematically overestimates pressures in chronic lung disease, except in severe PH [69-71]. This discordance has caused some clinicians to underuse echocardiography in screening for $\mathrm{PH}$ and may account for the fact that an echocardiographic RVSP $>50 \mathrm{~mm}$ is associated with increased mortality in IPF, whereas echocardiographic pressures of 35-50 $\mathrm{mm}$ are not.

Other ancillary tests include BNP levels and HRCT. BNP levels $>20 \mathrm{pmol} \cdot \mathrm{L}^{-1}$ are associated with a 14 -fold increase in mortality over patients with BNP $<4 \mathrm{pmol} \cdot \mathrm{L}^{-1}[72]$. A combination of elevated BNP levels and sPAP at echocardiography is predictive of increased mortality over either individual test [73].

An increased pulmonary artery diameter and an increase in the ratio of pulmonary artery diameter/ ascending aorta diameter $(>1.0)$ have both been reported as predictive of findings at RHC [74]. Although neither sign appears to be sufficiently accurate in isolation, the combination of HRCT and echocardiography was found in one study to perform better in $\mathrm{PH}$ detection than the use of either individual test [75].

\section{Treatment}

Important management considerations include identification and treatment of various contributing factors (obstructive sleep apnoea (OSA), pulmonary embolism (PE) and left heart failure); reversal of hypoxia and transplantation referral are equally important. Use of supplementary oxygen in order to maintain saturation $>90 \%$ at rest or during exercise, diuretics and, in the context of OSA, use of continuous positive airway pressure (CPAP) machines are advisable.

No formal role has been established for targeted PH therapy in ILD. Trial data have been conflicting although provide some evidence for a likely treatment effect. A distinction should be made between trials of targeted PH therapies in larger ILD populations (in the hope of a combined vascular and interstitial effect) and trials in ILD-PH patients.

Vasodilators have been used cautiously in IPF patients, due to the potential risk of worsened gas exchange and hypoxaemia. Sildenafil appears to cause selective pulmonary vasodilation, with maintenance of ventilation/perfusion $\left(V^{\prime} / Q^{\prime}\right)$ matching and arterial oxygenation [76]. When used in patients with advanced IPF, sildenafil was associated with a placebo-controlled improvement in DLCO and arterial oxygenation [77], indicating that a deleterious effect on $V^{\prime} / Q^{\prime}$ matching, if present in some patients, was, on average, relatively minor, compared to the benefits of treatment on the pulmonary vasculature. In IPF, the combination of an antifibrotic drug with sildenafil in moderate-to-severe $\mathrm{PH}$ is attractive in principle, as it targets both the 
interstitial and vascular compartments [16]. Bosentan was found to be nonefficacious in two large placebo-controlled IPF trials [78, 79] and in another large placebo-controlled evaluation in IPF, ambrisentan was associated with increased risk of disease progression and respiratory hospitalisations [80]. A recent trial of macitentan in IPF was also unsuccessful [81]. Taken together, these data provide no support for an antifibrotic interstitial effect of these therapies, despite supportive pre-clinical data.

In PH-ILD, sildenafil appears to be safe and well tolerated, and has had a significant effect on 6-min walk distance (6MWD) and BNP levels but not on RVSP after 6 months of treatment in small cohorts [82]. In sarcoidosis, sildenafil has improved mean pulmonary arterial pressure and cardiac output in repeat RHC 4 months after treatment [83]. By contrast, bosentan was found to be entirely nonefficacious in fibrotic IIP-PH [57] but may have beneficial effects in some sarcoidosis-PH patients, especially in patients with $\mathrm{PH}$ and limited ILD, although the fragmentary nature of current data must be emphasised [84-87]. Ambrisentan appears to be poorly tolerated in sarcoidosis- $\mathrm{PH}$ [88]. In an open-label, uncontrolled ILD-PH trial, riociguat, a stimulator of the soluble guanylate cyclase, was shown to increase cardiac output, decrease PVR and improve exercise capacity as judged by the effect in the 6MWT [89]. There are no studies regarding treatment of $\mathrm{PH}$ in the context of SSc-ILD and our knowledge comes from larger $\mathrm{PH}$ studies in which patients with SSc-PH were included. Combination therapy with endothelin receptor antagonists, phosphodiesterase type- 5 inhibitors and prostacyclin analogues did not affect survival but had effects on multiple outcome measures such as 6MWD, functional class and quality of life [62].

\section{Cardiac disease}

Cardiac disease can represent a comorbidity but also a consequence of direct involvement of the heart, as in the case of sarcoidosis or in IIMs. Major diagnostic uncertainties may occur in patients with ILD due to the presence of occult cardiac disease. An AE attributed initially to the underlying ILD may, in reality, be a rapid deterioration due to an exacerbation of cardiac disease. In patients with breathlessness disproportionate to the extent of the underlying ILD, proactive cardiac evaluation is warranted. HRCT findings such as profuse septal thickening, ground-glass opacities with patchy distribution and pleural effusions are suggestive of cardiac failure as a cause of rapid deterioration. In moderate-to-advanced fibrosing ILDs, a low threshold for 24-h Holter monitoring is appropriate if there is reason to suspect cardiac arrhythmias triggered by exertional hypoxia.

In historical IPF series, cardiac disease was one of the major causes of death [90]. In IPF, the prevalence of coronary artery disease (CAD) is high $(60 \%)$, probably as a consequence of smoking; associated with worse survival; and, importantly, is significant but unrecognised in $20 \%$ of cases [91, 92]. In this regard, HRCT can be helpful as the presence of moderate-to-severe coronary calcification has a high sensitivity and specificity for the presence of significant CAD, whereas absence of calcification has an extremely high negative predictive value [93].

Cardiac sarcoidosis is clinically overt in 5\% of patients but is present in $20-30 \%$ at autopsy, including patients with isolated cardiac disease without involvement of other major organs [94-97]. However, dyspnoea from cardiac disease may also result from left ventricular diastolic dysfunction due to age or arterial hypertension, or $\mathrm{PH}$, even in the absence of pulmonary fibrosis [98]. Arrhythmias are a common manifestation: sarcoidosis may present with complete heart block or sudden death. In adults aged $<55$ years with unexplained atrioventricular block or ventricular tachycardia of new onset, a high suspicion of underlying sarcoidosis is warranted [99, 100]. In addition to routine investigations performed to identify systemic support for a diagnosis of sarcoidosis, advanced cardiac imaging (i.e. cardiac magnetic resonance (CMR) or fluorodeoxyglucose positron emission tomography (FDG-PET)) is now routinely advocated as a sensitive method of detecting typical patterns of cardiac involvement. Advanced imaging also offers advantages in prognostic evaluation. Apart from identifying severe left ventricular dysfunction, in itself a malignant prognostic determinant [98], CMR [101] or FDG-PET [102-104] evidence of active disease is strongly predictive of future death or ventricular tachycardia. The first-line treatment of cardiac sarcoidosis is high-dose corticosteroid therapy, which tends to be more efficacious in patients with atrioventricular conduction disease or mild-to-moderate left ventricular dysfunction than in severe left ventricular dysfunction [105]. Patients with the diagnosis of cardiac sarcoidosis and sustained second or third degree of atrioventricular block and/or sustained ventricular tachycardia and/or left ventricular ejection fraction $<30 \%$ should undergo implantable cardioverter defibrillator placement [99].

Amongst the CTDs, cardiac involvement is most prevalent in SSc [106] and IIM, in which cardiac disease is the third to most frequent cause of death after lung disease and malignancies [107]. Subclinical disease is more frequent than clinically relevant cardiac disease. Heart failure, valve disease, CAD, myocarditis and bundle branch block have all been identified in IIMs. ECG, echocardiography and magnetic resonance imaging should be performed if there is a suspicion of cardiac involvement. Cardiac troponin I is a 
specific cardiac enzyme that allows myocardial inflammation to be identified when there is coexisting peripheral muscle involvement and elevation of creatine phosphokinase levels. In the absence of controlled data, intravenous steroid therapy with or without other immunosuppressive drugs has been used empirically, in combination with standard treatment for arrhythmias and heart failure.

Drug-induced lung disease resulting from cardiac therapies is suspected most commonly with the use of amiodarone or statins. Amiodarone, a widely used antiarrhythmic drug, has been associated with various patterns of lung toxicity and generally manifests with cough, dyspnoea and new infiltrates on HRCT. Statins, widely used to reduce cardiovascular morbidity in patients with known risk factors, have been implicated in the development of pulmonary fibrosis [108]. Statin-induced lung disease is commonly suspected, due to the widespread use of these agents, but is very rare, accounting for the absence of a demonstrable association between the use of statins and the development of ILD in a large epidemiological study [109]. This observation does not refute the existence of statin-induced lung disease, for which the evidence is sometimes compelling in individual patients.

Drug-induced lung disease, primarily a diagnosis of exclusion, is increased in likelihood when there is a temporal association between drug introduction and the onset of lung disease. Further supportive evidence includes the presence of a BAL eosinophilia and stability or improvement of lung disease after drug withdrawal. Decisions to withdraw cardiac therapies in suspected drug-induced lung disease must be made on a case-by-case basis, balancing the likelihood of the diagnosis against the necessity of continuing therapy on cardiac grounds.

\section{Pulmonary embolism}

Patients with IIPs are at increased risk of venous thromboembolic disease [110, 111]. Possible explanations include the presence of a procoagulant microenvironment in IPF [112], and immobility due to dyspnoea or to joint and muscle pains and stiffness in the particular case of CTD-ILDs. Computed tomography (CT) pulmonary angiography is the investigation of choice since it effectively excludes thromboembolism and can provide useful ancillary diagnostic information (e.g. typical CT features of cardiac failure). $V^{\prime} / Q^{\prime}$ scanning is highly nonspecific for PE in ILD as perfusion defects are almost invariably present. In a study of patients with IPF undergoing concurrent $V^{\prime} / Q^{\prime}$ scanning and HRCT, $V^{\prime} / Q^{\prime}$ mismatch, frequently seen in IPF scintigrams suggestive of PE, corresponded to honeycombing or emphysematous change seen on HRCT [113]. Honeycomb cysts are usually normally ventilated but not perfused.

In other settings, $\mathrm{PE}$ is routinely treated with vitamin $\mathrm{K}$ antagonists such as warfarin. However, the use of warfarin in a placebo-controlled trial in IPF was associated with increased mortality, raising the possibility that pro-coagulant mechanisms may be protective against disease progression in IPF $[114,115]$, despite the fact that pro-coagulant states have been associated with an increased prevalence of IPF in one study [116]. One possible explanation is that by depleting vitamin $\mathrm{K}$ stores, warfarin reduces vitamin $\mathrm{K}$-dependent activation of matrix gla protein, an inhibitor of extracellular matrix calcification [117]. Based on this finding, it can be argued that low molecular weight heparin is preferable to warfarin as treatment for PE occurring in IPF patients [118]. It is uncertain whether this caveat also applies to the use of new oral anticoagulants such as factor $\mathrm{Xa}$ inhibitors. Venous thromboembolism heparin prophylaxis remains appropriate in hospitalised ILD patients and there are no data suggesting that vitamin $\mathrm{K}$ antagonists for PE are contraindicated in ILDs other than IPF.

Recurrent episodes of PE in systemic lupus erythematosus (SLE) should prompt the exclusion of secondary antiphospholipid syndrome (APS), associated with lupus anticoagulant positivity or the presence of anti-cardiolipin or anti- $\beta 2$-glycoprotein 1 antibodies. The treatment of PE due to APS does not differ from standard PE therapy. Immunosuppression does not seem to halt thrombotic recurrences [119]. Interestingly, hydroxychloroquine therapy is associated with a lower likelihood of persistent lupus anticoagulant positivity in SLE and may have a useful prophylactic role [120].

\section{Lung cancer}

The prevalence of lung cancer in IPF varies from $4.4 \%$ to $9.8 \%$ [121]. Lung cancers in IPF tend to be peripheral and located in the lower lobes, which is in accordance with the distribution of the fibrotic lesions in IPF, suggesting that the fibrotic process may play a role in the development of cancer, with smoking a common risk factor [122]. Lung cancer often manifests as a mass-like lesion in or near areas of fibrosis; distinction between malignancy and areas of confluent fibrosis may be difficult, especially when previous imaging is unavailable. Lung cancer can also develop in CTDs (mainly SSc) but is rare in sarcoidosis, probably reflecting the inverse correlation between sarcoidosis and smoking [123, 124]. Diagnosis and staging of lung cancer in ILDs should be undertaken as for any other patient. The main dilemma for the clinician arises when these diseases, each one with a very poor outcome, have been 
diagnosed in the same patient. Median survival after diagnosis is worse in lung cancer-ILD than in either ILD or lung cancer alone [125-127].

Treatment options are the same as in lung cancer and the main complication is drug-induced ILD, presenting with AEILD. There are no specific guidelines and therefore management should be based on risk/benefit considerations. A single study has raised concerns about the use of stereotactic body radiotherapy in severe ILD because of a high risk of radiation pneumonitis. In subclinical disease, radiotherapy has been shown to be relatively safe with a low risk of radiation pneumonitis extending beyond the irradiated field [128]. Chemotherapy-induced acute exacerbations of lung disease have an incidence of $8.7-21 \%$ [129]. The combination of carboplatin with etoposide and of carboplatin with paclitaxel was efficacious in two small studies of patients with IIPs and small cell lung carcinoma and non-small cell lung carcinoma (NSCLC), respectively. When the authors integrated the two groups, in 35 patients, they observed 10 AEs, but in only two cases was there temporal linkage to this specific chemotherapy regimen $[129,130]$.

Epithelial growth factor receptor (EGFR) tyrosine kinase inhibitors (TKIs) are widely used in the treatment of NSCLC with active EGFR mutations. They have been associated with drug-induced ILD and fatal ILDs. The risk is higher in patients who receive EGFR-TKIs in association with or after chemotherapy [131]. Nintedanib, an intracellular inhibitor recently recommended for the treatment of IPF, targets multiple tyrosine kinases receptors, and is also used in the treatment of NSCLC and ovarian cancer. A literature search has not revealed any study suggesting that nintedanib can be related with the development of drug-induced ILD.

AEILD, the most dangerous complication after pulmonary resection for primary lung cancer, is associated with low pre-operative $\mathrm{DLCO}$ and $\mathrm{KCO}, \mathrm{FVC}<80 \%$ predicted, and lactate dehydrogenase $>400 \mathrm{IU} \cdot \mathrm{L}^{-1}$ [132-134]. However, it should be stressed that in CPFE, spirometry in isolation may be misleading because $\mathrm{CPFE}$ is characterised by spurious preservation of lung volumes. A composite physiologic index $>40$ is associated with $50 \%$ chance of post-operative acute respiratory distress syndrome [132]. The extent of resection is also important as the risk is higher with pneumectomy than with lobectomy. If pneumectomy is needed for complete resection, a detailed risk/benefit discussion with the patient is required [132]. Duration of one-lung ventilation and the manipulation of nonresected lung tissue both contribute to oxidative stress and, thus, to the development of post-operative AEILD, and should both be minimised [135].

\section{Sleep disorders}

In early series examining the association, the prevalence of OSA in IPF was reported to vary from $60 \%$ to $90 \%[136,137]$. In sarcoidosis and SSc-ILD, the prevalence also seems to be increased (52\% and $66 \%$, respectively) $[138,139]$. However, these observations, in themselves, have produced more questions than answers, especially with regard to the indications for and efficacy of standard OSA therapy in IPF. In the general community, the prevalence of OSA is $\sim 20 \%$ in older adults [140]. However, OSA is not screened for routinely but tends to be investigated when there is a high perceived risk, judging from daytime somnolence (quantified using validated scales). In the largest early series, the Epworth Sleepiness Scale score correlated poorly with the severity of OSA at nocturnal polysomnography (NPSG) [137]. In a recent series, $<25 \%$ of IPF patients with sleep disordered breathing had an OSA clinical syndrome (with compatible Epworth Sleepiness Scale scores) [141].

The distinction is important. IPF patients have an impaired pulmonary vascular reserve, which is likely to influence the severity of desaturation during apnoeic episodes, in keeping with observed links between nocturnal oxygen desaturation and markers of pulmonary vasculopathy [142]. Thus, it is not clear whether the NPSG profile of OSA is, in itself, a malignant prognostic determinant in IPF or is merely a marker of the adverse outcome associated with pulmonary hypertension. Should OSA treatment be instituted in all IPF patients with characteristic NPSG features, in order to improve life expectancy, or only in those IPF patients with daytime somnolence, in order to improve quality of life? The latter goal appears logical but more work is needed to show that failure to treat OSA has outcome implications. Worse outcomes observed in IPF patients who do not comply with CPAP are inconclusive in this regard because difficulties with the use of CPAP machines may be more prevalent in advanced IPF [143]. An increase in mortality in IPF patients with OSA might, in theory, be linked to the promotion of GOR but this view is not supported by a study of 54 patients in which GOR promotion by OSA was definitively refuted [144]. Failure to treat OSA might, in principle, lead to worsening $\mathrm{PH}$, triggered by the severity of desaturation, but if so, it is entirely uncertain whether this danger might be alleviated, at least in some patients, by nocturnal oxygen supplementation alone, without the need for routine institution of CPAP.

With regard to treatment, the most important issue is related to reduced compliance of patients with the CPAP machine for several reasons [143]. Nocturnal dry and irritating cough is a frequent symptom leading 
to impairment of sleep quality. The use of heated humidification before or after CPAP titration is often helpful whereas the use of codeine-based drugs is questionable because of the effect on respiratory drive. Claustrophobia can be related to the rapid and shallow breathing pattern of these patients, and an initial trial with CPAP at low pressures may be helpful. Mood disorders and, especially, depression are common. Antidepressants have dual benefits in improving depression and reducing the severity of OSA [145, 146]. The use of steroids in ILDs other than IPF can have impact on sleep leading to insomnia and multiple nocturnal wakening $[147,148]$ as well as to central fat deposition in the neck region and deterioration of underlying OSA. Therefore, longer term titration of CPAP treatment is needed. Taken together, these considerations amply justify routine referral to sleep centres for the diagnosis and management of OSA in ILD.

\section{Depression}

Depression and anxiety are highly prevalent in patients with ILD. In a mixed ILD cohort [149, 150], clinically relevant depression was observed in $>20 \%$ of patients. Independent predictors of depression include severity of dyspnoea, sleep quality, reduced FVC, pain and functional status [149]. Corticosteroids may also play a role in precipitating depression. In IPF, the prevalence of depression varies from $11 \%$ to $50 \%$ according to the tools used for the assessment of depression [149, 151, 152]. In ILD patients, depression has a definite impact on quality of life and on adherence to treatments [153-155]. In a recent study, the Medical Research Council score was an independent predictor of anxiety and depression in a mixed ILD cohort, in which the rates of anxiety and depression were increased without a specific predilection in any individual disease entity [156]. Importantly, prior to attending a specialised ILD centre, $<2 \%$ of patients had an established diagnosis of depression. At the initial visit, following the completion of the HADS (Hospital Anxiety and Depression Scale), a tool to measure anxiety and depression in a hospital setting, depression was identified in $23 \%$ of the patients, with clinically significant depression present in $7 \%$ of patients. These findings support early referral of ILD patients to specialised ILD centres with access to expert psychiatric advice. It has been proposed that ILD patients with functional impairment should be referred for pulmonary rehabilitation, based on observed benefits on fatigue and functional capacity, and improvements in symptoms of depression and anxiety [157]. Whether all ILD patients should be screened routinely for depression and anxiety merits further investigation [149].

\section{Conclusion}

In ILD, the comorbidities discussed in this review have in common the potential to impair quality of life and to reduce life expectancy. Comorbidities can also have a major impact on case-by-case treatment decisions; for example, antifibrotic therapy is less likely to prolong life in IPF patients with advanced lung cancer or severe $\mathrm{PH}$. With an increasing focus on IPF-specific antifibrotic treatments and on immunomodulation in patients with other forms of ILD, there is a danger that the importance of comorbidities may be underestimated, especially when their effect on cardiopulmonary reserve is chronic and insidiously progressive. The early detection and accurate management of the comorbidities discussed in this review have major potential benefits in reducing morbidity and mortality.

\section{References}

1 Hyldgaard C, Hilberg O, Bendstrup E. How does comorbidity influence survival in idiopathic pulmonary fibrosis? Respir Med 2014; 108: 647-653.

2 Kreuter M, Ehlers-Tenenbaum S, Palmowski K, et al. Impact of comorbidities on mortality in patients with idiopathic pulmonary fibrosis. PLoS One 2016; 11: e0151425.

3 Song JW, Hong SB, Lim CM, et al. Acute exacerbation of idiopathic pulmonary fibrosis: incidence, risk factors and outcome. Eur Respir J 2011; 37: 356-363.

4 Wootton SC, Kim DS, Kondoh Y, et al. Viral infection in acute exacerbation of idiopathic pulmonary fibrosis. Am J Respir Crit Care Med 2011; 183: 1-30.

5 Lasithiotaki I, Antoniou KM, Vlahava VM, et al. Detection of herpes simplex virus type-1 in patients with fibrotic lung diseases. PLoS One 2011; 6: e27800.

6 Molyneaux PL, Cox MJ, Willis-Owen SA, et al. The role of bacteria in the pathogenesis and progression of idiopathic pulmonary fibrosis. Am J Respir Crit Care Med 2014; 190: 906-913.

7 Fingerlin TE, Murphy E, Zhang W, et al. Genome-wide association study identifies multiple susceptibility loci for pulmonary fibrosis. Nat Genet 2013; 45: 613-620.

8 Stock CJ, Sato H, Fonseca C, et al. Mucin 5B promoter polymorphism is associated with idiopathic pulmonary fibrosis but not with development of lung fibrosis in systemic sclerosis or sarcoidosis. Thorax 2013; 68: 436-441.

9 Idiopathic Pulmonary Fibrosis Clinical Research Network, Raghu G, Anstrom KJ, et al. Prednisone, azathioprine, and $N$-acetylcysteine for pulmonary fibrosis. N Engl J Med 2012; 366: 1968-1977.

10 Raghu G, Rochwerg B, Zhang Y, et al. An official ATS/ERS/JRS/ALAT clinical practice guideline: treatment of idiopathic pulmonary fibrosis. An update of the 2011 clinical practice guideline. Am J Respir Crit Care Med 2015; 192: e3-e19.

11 Li H, Zhou Y, Fan F, et al. Effect of azithromycin on patients with diffuse panbronchiolitis: retrospective study of 521 cases. Intern Med 2011; 50: 1663-1669.

12 Wong C, Jayaram L, Karalus N, et al. Azithromycin for prevention of exacerbations in non-cystic fibrosis bronchiectasis (EMBRACE): a randomised, double-blind, placebo-controlled trial. Lancet 2012; 380: 660-667. 
Spagnolo P, Fabbri LM, Bush A. Long-term macrolide treatment for chronic respiratory disease. Eur Respir $J$ 2013; 42: 239-251.

Wuyts WA, Willems S, Vos R, et al. Azithromycin reduces pulmonary fibrosis in a bleomycin mouse model. Exp Lung Res 2010; 36: 602-614.

Shulgina L, Cahn AP, Chilvers ER, et al. Treating idiopathic pulmonary fibrosis with the addition of co-trimoxazole: a randomised controlled trial. Thorax 2013; 68: 155-162.

Wuyts WA, Antoniou KM, Borensztajn K, et al. Combination therapy: the future of management for idiopathic pulmonary fibrosis? Lancet Respir Med 2014; 2: 933-942.

Collard HR, Moore BB, Flaherty KR, r, et al. Acute exacerbations of idiopathic pulmonary fibrosis. Am J Respir Crit Care Med 2007; 176: 636-643.

Antoniou KM, Wells AU. Acute exacerbations of idiopathic pulmonary fibrosis. Respiration 2013; 86: 265-274. Ryerson CJ, Cottin V, Brown KK, et al. Acute exacerbation of idiopathic pulmonary fibrosis: shifting the paradigm. Eur Respir J 2015; 46: 512-520.

Simon-Blancal V, Freynet $\mathrm{O}$, Nunes $\mathrm{H}$, et al. Acute exacerbation of idiopathic pulmonary fibrosis: outcome and prognostic factors. Respiration 2012; 83: 28-35.

Collard HR, Yow E, Richeldi L, et al. Suspected acute exacerbation of idiopathic pulmonary fibrosis as an outcome measure in clinical trials. Respir Res 2013; 14: 73.

Corte TJ, Wells AU. Diffuse alveolar damage in idiopathic pulmonary fibrosis: does aetiology matter? Respirology 2010; 15: 873-875.

Huie TJ, Olson AL, Cosgrove GP, et al. A detailed evaluation of acute respiratory decline in patients with fibrotic lung disease: aetiology and outcomes. Respirology 2010; 15: 909-917.

Kameda $\mathrm{H}$, Tokuda $\mathrm{H}$, Sakai $\mathrm{F}$, et al. Clinical and radiological features of acute-onset diffuse interstitial lung diseases in patients with rheumatoid arthritis receiving treatment with biological agents: importance of Pneumocystis pneumonia in Japan revealed by a multicenter study. Intern Med 2011; 50: 305-313.

Wells AU. The clinical utility of bronchoalveolar lavage in diffuse parenchymal lung disease. Eur Respir Rev 2010; 19: 237-241.

Smith NL, Denning DW. Underlying conditions in chronic pulmonary aspergillosis including simple aspergilloma. Eur Respir J 2011; 37: 865-872.

Park SW, Song JW, Shim TS, et al. Mycobacterial pulmonary infections in patients with idiopathic pulmonary fibrosis. J Korean Med Sci 2012; 27: 896-900.

Kousha M, Tadi R, Soubani AO. Pulmonary aspergillosis: a clinical review. Eur Respir Rev 2011; 20: 156-174.

Limper AH, Knox KS, Sarosi GA, et al. An official American Thoracic Society statement: treatment of fungal infections in adult pulmonary and critical care patients. Am J Respir Crit Care Med 2011; 183: 96-128.

Keir GJ, Garfield B, Hansell DM, et al. Cyclical caspofungin for chronic pulmonary aspergillosis in sarcoidosis. Thorax 2013; 69: 287-288.

Gupta D, Kumar S, Aggarwal AN, et al. Interferon gamma release assay (QuantiFERON-TB Gold In Tube) in patients of sarcoidosis from a population with high prevalence of tuberculosis infection. Sarcoidosis Vasc Diffuse Lung Dis 2011; 28: 95-101.

Brandt D, Gershwin ME. Common variable immune deficiency and autoimmunity. Autoimmun Rev 2006; 5: 465-470.

Bouvry D, Mouthon L, Brillet PY, et al. Granulomatosis associated CVID: a case-control versus sarcoidosis study. Eur Respir J 2013; 41: 115-122.

Savarino E, Carbone R, Marabotto E, et al. Gastro-oesophageal reflux and gastric aspiration in idiopathic pulmonary fibrosis patients. Eur Respir J 2013; 42: 1322-1331.

Raghu G, Amatto VC, Behr J, et al. Comorbidities in idiopathic pulmonary fibrosis patients: a systematic literature review. Eur Respir J 2015; 46: 1113-1130.

Tobin RW, Pope CEII, Pellegrini CA, et al. Increased prevalence of gastroesophageal reflux in patients with idiopathic pulmonary fibrosis. Am J Respir Crit Care Med 1998; 158: 1804-1808.

Patti MG, Tedesco P, Golden J, et al. Idiopathic pulmonary fibrosis: how often is it really idiopathic? J Gastrointest Surg 2005; 9: 1053-1056.

Raghu G, Freudenberger TD, Yang S, et al. High prevalence of abnormal acid gastro-oesophageal reflux in idiopathic pulmonary fibrosis. Eur Respir J 2006; 27: 136-142.

Salvioli B, Belmonte G, Stanghellini V, et al. Gastrooesophageal reflux and interstitial lung disease. Dig Liver Dis 2006; 38: 879-884.

Sweet MP, Patti MG, Leard LE, et al. Gastroesophageal reflux in patients with idiopathic pulmonary fibrosis referred for lung transplantation. J Thorac Cardiovasc Surg 2007; 133: 1078-1084.

Cantu EIII, Appel JZIII, Hartwig MG, et al. Early fundoplication prevents chronic allograft dysfunction in patients with gastroesophageal reflux disease. Ann Thorac Surg 2004; 78: 1142-1151.

Raghu G, Yang ST, Spada C, et al. Sole treatment of acid gastroesophageal reflux in idiopathic pulmonary fibrosis: a case series. Chest 2006; 129: 794-800.

Tcherakian C, Cottin V, Brillet PY, et al. Progression of idiopathic pulmonary fibrosis: lessons from asymmetrical disease. Thorax 2011; 66: 226-231.

Lee JS, Song JW, Wolters PJ, et al. Bronchoalveolar lavage pepsin in acute exacerbation of idiopathic pulmonary fibrosis. Eur Respir J 2012; 39: 352-358.

Lee JS, Collard HR, Anstrom KJ, et al. Anti-acid treatment and disease progression in idiopathic pulmonary fibrosis: an analysis of data from three randomised controlled trials. Lancet Respir Med 2013; 1: 369-376.

Kreuter M, Wuyts W, Renzoni E, et al. Antacid therapy and disease outcomes in idiopathic pulmonary fibrosis: a pooled analysis. Lancet Respir Med 2016; 4: 381-389.

Raghu G, Crestani B, Bailes Z, et al. Effect of anti-acid medication on reduction in FVC decline with nintedanib. Eur Respir J 2015; 46: Suppl. 59, OA4502.

Linden PA, Gilbert RJ, Yeap BY, et al. Laparoscopic fundoplication in patients with end-stage lung disease awaiting transplantation. J Thorac Cardiovasc Surg 2006; 131: 438-446.

Noth I, Zangan SM, Soares RV, et al. Prevalence of hiatal hernia by blinded MDCT in patients with IPF. Eur Respir J 2012; 39: 344-351. 
Downing TE, Sporn TA, Bollinger RR, et al. Pulmonary histopathology in an experimental model of chronic aspiration is independent of acidity. Exp Biol Med (Maywood) 2008; 233: 1202-1212.

Savarino E, Bazzica M, Zentilin P, et al. Gastroesophageal reflux and pulmonary fibrosis in scleroderma: a study using pH-impedance monitoring. Am J Respir Crit Care Med 2009; 179: 408-413.

Antoniou KM, Margaritopoulos G, Economidou F, et al. Pivotal clinical dilemmas in collagen vascular diseases associated with interstitial lung involvement. Eur Respir J 2009; 33: 882-896.

Wells AU, Margaritopoulos GA, Antoniou KM, et al. Interstitial lung disease in systemic sclerosis. Semin Respir Crit Care Med 2014; 35: 213-221.

Christmann RB, Wells AU, Capelozzi VL, et al. Gastroesophageal reflux incites interstitial lung disease in systemic sclerosis: clinical, radiologic, histopathologic, and treatment evidence. Semin Arthritis Rheum 2010; 40: 241-249.

Galiè N, Humbert M, Vachiery JL, et al. 2015 ESC/ERS Guidelines for the diagnosis and treatment of pulmonary hypertension. Eur Respir J 2015; 46: 1855-1856.

Latsi PI, du Bois RM, Nicholson AG, et al. Fibrotic idiopathic interstitial pneumonia: the prognostic value of longitudinal functional trends. Am J Respir Crit Care Med 2003; 168: 531-537.

Corte TJ, Keir GJ, Dimopoulos K, et al. Bosentan in pulmonary hypertension associated with fibrotic idiopathic interstitial pneumonia. Am J Respir Crit Care Med 2014; 190: 208-217. 2013; 22: 292-301

Judge EP, Fabre A, Adamali HI, et al. Acute exacerbations and pulmonary hypertension in advanced idiopathic pulmonary fibrosis. Eur Respir J 2012; 40: 93-100.

Corte TJ, Wort SJ, Wells AU. Pulmonary hypertension in idiopathic pulmonary fibrosis: a review. Sarcoidosis Vasc Diffuse Lung Dis 2009; 26: 7-19.

Corte TJ, Wells AU, Nicholson AG, et al. Pulmonary hypertension in sarcoidosis: a review. Respirology 2011; 16: 69-77.

Solomon JJ, Olson AL, Fischer A, et al. Scleroderma lung disease. Eur Respir Rev 2013; 22: 6-19. diffuse fibrotic lung disease and suspected pulmonary hypertension. Thorax 2009; 64: 883-888.

Corte TJ, Wort SJ, MacDonald PS, et al. Pulmonary function vascular index predicts prognosis in idiopathic interstitial pneumonia. Respirology 2012; 17: 674-680

Coghlan JG, Denton CP, Grünig E, et al. Evidence-based detection of pulmonary arterial hypertension in systemic sclerosis: the DETECT study. Ann Rheum Dis 2014; 73: 1340-1349.

Antoniou KM, Margaritopoulos GA, Goh NS, et al. Combined pulmonary fibrosis and emphysema in scleroderma lung disease has a major confounding effect on lung physiology and screening for pulmonary hypertension. Arthritis Rheumatol 2016; 68: 1004-1012.

Hamada K, Nagai S, Tanaka S, et al. Significance of pulmonary arterial pressure and diffusion capacity of the lung as prognosticator in patients with idiopathic pulmonary fibrosis. Chest 2007; 131: 650-656.

Lettieri CJ, Nathan SD, Barnett SD, et al. Prevalence and outcomes of pulmonary arterial hypertension in advanced idiopathic pulmonary fibrosis. Chest 2006; 129: 746-752.

Arcasoy SM, Christie JD, Ferrari VA, et al. Echocardiographic assessment of pulmonary hypertension in patients with advanced lung disease. Am J Respir Crit Care Med 2003; 167: 735-740.

Denton CP, Cailes JB, Phillips GD, et al. Comparison of Doppler echocardiography and right heart catheterization to assess pulmonary hypertension in systemic sclerosis. Br J Rheumatol 1997; 36: 239-243.

Nadrous HF, Pellikka PA, Krowka MJ, et al. Pulmonary hypertension in patients with idiopathic pulmonary fibrosis. Chest 2005; 128: 2393-2399.

Corte TJ, Wort SJ, Gatzoulis MA, et al. Elevated brain natriuretic peptide predicts mortality in interstitial lung disease. Eur Respir J 2010; 36: 819-825.

Song JW, Song JK, Kim DS. Echocardiography and brain natriuretic peptide as prognostic indicators in idiopathic pulmonary fibrosis. Respir Med 2009; 103: 180-186.

Ng CS, Wells AU, Padley SP. A CT sign of chronic pulmonary arterial hypertension: the ratio of main pulmonary artery to aortic diameter. J Thorac Imaging 1999; 14: 270-278.

Devaraj A, Wells AU, Meister MG, et al. Detection of pulmonary hypertension with multidetector CT and echocardiography alone and in combination. Radiology 2010; 254: 609-616.

Milara J, Escrivá J, Ortiz JL, et al. Vascular effects of sildenafil in patients with pulmonary fibrosis and pulmonary hypertension: an ex vivo/in vitro study. Eur Respir J 2016; 47: 1737-1749.

Idiopathic Pulmonary Fibrosis Clinical Research Network. A controlled trial of sildenafil in advanced idiopathic pulmonary fibrosis. N Engl J Med 2010; 363: 620-628.

King TE Jr, Behr J, Brown KK, et al. BUILD-1: a randomized placebo-controlled trial of bosentan in idiopathic pulmonary fibrosis. Am J Respir Crit Care Med 2008; 177: 75-81.

King TE Jr, Brown KK, Raghu G, et al. BUILD-3: a randomized, controlled trial of bosentan in idiopathic pulmonary fibrosis. Am J Respir Crit Care Med 2011; 184: 92-99.

Raghu G, Behr J, Brown KK, et al. Treatment of idiopathic pulmonary fibrosis with ambrisentan: a parallel, randomized trial. Ann Intern Med 2013; 158: 641-649.

Raghu G, Million-Rousseau R, Morganti A, et al. Macitentan for the treatment of idiopathic pulmonary fibrosis: the randomised controlled MUSIC trial. Eur Respir J 2013; 42: 1622-1632.

Corte TJ, Gatzoulis MA, Parfitt L, et al. The use of sildenafil to treat pulmonary hypertension associated with interstitial lung disease. Respirology 2010; 15: 1226-1232.

Milman N, Burton CM, Iversen $\mathrm{M}$, et al. Pulmonary hypertension in end-stage pulmonary sarcoidosis: therapeutic effect of sildenafil? J Heart Lung Transplant 2008; 27: 329-334.

Foley RJ, Metersky ML. Successful treatment of sarcoidosis associated pulmonary hypertension with bosentan. Respiration 2008; 75: 211-214.

Sharma S, Kashour T, Philipp R. Secondary pulmonary arterial hypertension: treated with endothelin receptor blockade. TexHeart Inst J 2005; 32: 405-410.

Pitsiou GG, Spyratos D, Kioumis I, et al. Sarcoidosis-associated pulmonary hypertension: a role for endothelin receptor antagonists? Ther Adv Respir Dis 2009; 3: 99-101. 
Barnett CF, Bonura EJ, Nathan SD, et al. Treatment of sarcoidosis-associated pulmonary hypertension. A two-center experience. Chest 2009; 135: 1455-1461.

Judson MA, Highland KB, Kwon S, et al. Ambrisentan for sarcoidosis associated pulmonary hypertension. Sarcoidosis Vasc Diffuse Lung Dis 2011; 28: 139-145.

Hoeper MM, Halank M, Wilkens $\mathrm{H}$, et al. Riociguat for interstitial lung disease and pulmonary hypertension: a pilot trial. Eur Respir J 2013; 41: 853-860.

Panos RJ, Mortenson RL, Niccoli SA, et al.. Clinical deterioration in patients with idiopathic pulmonary fibrosis: causes and assessment. Am J Med 1990; 88: 396-404.

Kizer JR, Zisman DA, Blumenthal NP, et al. Association between pulmonary fibrosis and coronary artery disease. Arch Intern Med 2004; 164: 551-556.

Nathan SD, Basavaraj A, Reichner C, et al. Prevalence and impact of coronary artery disease in idiopathic pulmonary fibrosis. Respir Med 2010; 104: 1035-1041.

Nathan SD, Weir N, Shlobin OA, et al. The value of computed tomography scanning for the detection of coronary artery disease in patients with idiopathic pulmonary fibrosis. Respirology 2011; 16: 481-486.

Baughman RP, Teirstein AS, Judson MA, et al. Clinical characteristics of patients in a case control study of sarcoidosis. Am J Respir Crit Care Med 2001; 164: 1885-1889.

Iwai K, Tachibana T, Takemura T, et al. Pathological studies on sarcoidosis autopsy. I. Epidemiological features of 320 cases in Japan. Acta Pathol Jpn 1993; 43: 372-376.

Perry A, Vuitch F. Causes of death in patients with sarcoidosis. A morphologic study of 38 autopsies with clinicopathologic correlations. Arch Pathol Lab Med 1995; 119: 167-172.

Tavora F, Cresswell N, Li L, et al. Comparison of necropsy findings in patients with sarcoidosis dying suddenly from cardiac sarcoidosis versus dying suddenly from other causes. Am J Cardiol 2009; 104: 571-577.

Rapti A, Kouranos V, Gialafos E, et al. Elevated pulmonary arterial systolic pressure in patients with sarcoidosis: prevalence and risk factors. Lung 2013; 191: 61-67.

Nery PB, Leung E, Birnie DH. Arrhythmias in cardiac sarcoidosis: diagnosis and treatment. Curr Opin Cardiol 2012; 27: 181-189.

Kandolin R, Lehtonen J, Kupari M. Cardiac sarcoidosis and giant cell myocarditis as causes of atrioventricular block in young and middle-aged adults. Circ Arrhythm Electrophysiol 2011; 4: 303-309.

Greulich S, Deluigi CC, Gloekler S, et al. CMR imaging predicts death and other adverse events in suspected cardiac sarcoidosis. JACC Cardiovasc Imaging 2013; 6: 501-511.

Ahmadian A, Brogan A, Berman J, et al. Quantitative interpretation of FDG PET/CT with myocardial perfusion imaging increases diagnostic information in the evaluation of cardiac sarcoidosis. J Nucl Cardiol 2014; 21: 925-939.

Blankstein $\mathrm{R}$, Osborne $\mathrm{M}$, Naya $\mathrm{M}$, et al. Cardiac positron emission tomography enhances prognostic assessments of patients with suspected cardiac sarcoidosis. J Am Coll Cardiol 2014; 63: 329-336.

Manabe $\mathrm{O}$, Yoshinaga $\mathrm{K}$, Ohira $\mathrm{H}$, et al. Right ventricular ${ }^{18} \mathrm{~F}-\mathrm{FDG}$ uptake is an important indicator for cardiac involvement in patients with suspected cardiac sarcoidosis. Ann Nucl Med 2014; 28: 656-663.

Sadek MM, Yung D, Birnie
Cardiol 2013; 29: 1034-1041.

Di Cesare E, Battisti S, Di Sibio A, et al. Early assessment of sub-clinical cardiac involvement in systemic sclerosis (SSc) using delayed enhancement cardiac magnetic resonance (CE-MRI). Eur J Radiol 2013; 82: e268-e273.

Van Gelder H, Charles-Schoeman C. The heart in inflammatory myopathies. Rheum Dis Clin North Am 2014; 40: $1-10$.

Fernandez AB, Karas RH, Alsheikh-Ali AA, et al. Statins and interstitial lung disease: a systematic review of the literature and of food and drug administration adverse event reports. Chest 2008; 134: 824-830.

Saad N, Camus P, Suissa S, et al. Statins and the risk of interstitial lung disease: a cohort study. Thorax 2013; 68: 361-364.

Hubbard RB, Smith C, Le Jeune I, et al. The association between idiopathic pulmonary fibrosis and vascular disease: a population-based study. Am J Respir Crit Care Med 2008; 178: 1257-1261.

Sprunger DB, Olson AL, Huie TJ, et al. Pulmonary fibrosis is associated with an elevated risk of thromboembolic disease. Eur Respir J 2012; 39: 125-132.

Chambers RC. Procoagulant signalling mechanisms in lung inflammation and fibrosis: novel opportunities for pharmacological intervention? Br J Pharmacol 2008; 153: S367-S378.

Strickland NH, Hughes JM, Hart DA, et al. Cause of regional ventilation-perfusion mismatching in patients with idiopathic pulmonary fibrosis: a combined CT and scintigraphic study. AJR Am J Roentgenol 1993; 161: 719-725.

Noth I, Anstrom KJ, Calvert SB, et al. A placebo-controlled randomized trial of warfarin in idiopathic pulmonary fibrosis. Am J Respir Crit Care Med 2012; 186: 88-95.

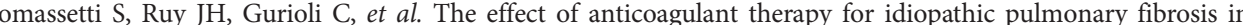
real life practice. Sarcoidosis Vasc Diffuse Lung Dis 2013; 30: 121-127.

Navaratnam V, Fogarty AW, McKeever T, et al. Presence of a prothrombotic state in people with idiopathic pulmonary fibrosis: a population-based case-control study. Thorax 2014; 69: 207-215.

Respir Crit Care Med 2016; 193: 700-701.

Margaritopoulos GA, Antoniou KM. Can warfarin be used in the treatment of pulmonary embolism in idiopathic pulmonary fibrosis? Am J Respir Crit Care Med 2016; 193: 810-811.

Vlachoyiannopoulos PG, Toya SP, Katsifis G, et al. Upregulation of antiphospholipid antibodies following cyclophosphamide therapy in patients with systemic lupus erythematosus. J Rheumatol 2008; 35: 1768-1775.

Broder A, Putterman C. Hydroxychloroquine use is associated with lower odds of persistently positive antiphospholipid antibodies and/or lupus anticoagulant in systemic lupus erythematosus. J Rheumatol 2013; 40: 30-33. Archontogeorgis K, Steiropoulos P, Tzouvelekis A, et al. Lung cancer and interstitial lung diseases: a systematic review. Pulm Med 2012; 2012: 315918.

Vancheri C, Failla M, Crimi N, et al. Idiopathic pulmonary fibrosis: a disease with similarities and links to cancer biology. Eur Respir J 2010; 35: 496-504.

Bonifazi M, Tramacere I, Pomponio G, et al. Systemic sclerosis (scleroderma) and cancer risk: systematic review and meta-analysis of observational studies. Rheumatology (Oxford) 2013; 52: 143-154. 
124 Bonifazi M, Bravi F, Gasparini S, et al. Sarcoidosis and cancer risk: systematic review and meta-analysis of observational studies. Chest 2015; 147: 778-791.

125 Tomassetti S, Gurioli C, Ryu JH, et al. The impact of lung cancer on survival of idiopathic pulmonary fibrosis. Chest 2015; 147: 157-164.

126 Girard N, Marchand-Adam S, Naccache JM, et al. Lung cancer in combined pulmonary fibrosis and emphysema: a series of 47 Western patients. J Thorac Oncol 2014; 9: 1162-1170.

127 Usui K, Tanai C, Tanaka Y, et al. The prevalence of pulmonary fibrosis combined with emphysema in patients with lung cancer. Respirology 2011; 16: 326-331.

128 Yamaguchi S, Ohguri T, Ide S, et al. Stereotactic body radiotherapy for lung tumors in patients with subclinical interstitial lung disease: the potential risk of extensive radiation pneumonitis. Lung Cancer 2013; 82: 260-265.

129 Minegishi Y, Kuribayashi H, Kitamura K, et al. The feasibility study of carboplatin plus etoposide for advanced small cell lung cancer with idiopathic interstitial pneumonias. J Thorac Oncol 2011; 6: 801-807.

130 Minegishi Y, Sudoh J, Kuribayasi H, et al. The safety and efficacy of weekly paclitaxel in combination with carboplatin for advanced non-small cell lung cancer with idiopathic interstitial pneumonias. Lung Cancer 2011; 71: 70-74.

131 Shi L, Tang J, Tong L, et al. Risk of interstitial lung disease with gefitinib and erlotinib in advanced non-small cell lung cancer: a systematic review and meta-analysis of clinical trials. Lung Cancer 2014; 83: 231-239.

132 Kumar P, Goldstraw P, Yamada K, et al. Pulmonary fibrosis and lung cancer: risk and benefit analysis of pulmonary resection. J Thorac Cardiovasc Surg 2003; 125: 1321-1327.

133 Park JS, Kim HK, Kim K, et al. Prediction of acute pulmonary complications after resection of lung cancer in patients with preexisting interstitial lung disease. Thorac Cardiovasc Surg 2011; 59: 148-152.

134 Koizumi K, Hirata T, Hirai K, et al. Surgical treatment of lung cancer combined with interstitial pneumonia: the effect of surgical approach on postoperative acute exacerbation. Ann Thorac Cardiovasc Surg 2004; 10: 340-346.

135 Misthos $\mathrm{P}$, Katsaragakis S, Milingos N, et al. Postresectional pulmonary oxidative stress in lung cancer patients. The role of one-lung ventilation. Eur J Cardiothorac Surg 2005; 27: 379-383.

136 Mermigkis C, Stagaki E, Tryfon S, et al. How common is sleep-disordered breathing in patients with idiopathic pulmonary fibrosis? Sleep Breath 2010; 14: 387-390.

137 Lancaster LH, Mason WR, Parnell JA, et al. Obstructive sleep apnea is common in idiopathic pulmonary fibrosis. Chest 2009; 136: 772-778.

138 Bingol Z, Pihtili A, Gulbaran Z, et al. Relationship between parenchymal involvement and obstructive sleep apnea in subjects with sarcoidosis. Clin Respir J 2015; 9: 14-21.

139 Pihtili A, Bingol Z, Kiyan E, et al. Obstructive sleep apnea is common in patients with interstitial lung disease. Sleep Breath 2013; 17: 1281-1288.

140 Hiestand DM, Britz P, Goldman M, et al. Prevalence of symptoms and risk of sleep apnea in the US population: results from the National Sleep Foundation Sleep in America 2005 Poll. Chest 2006; 130: 780-786.

141 Milioli G, Bosi M, Poletti V, et al. Sleep and respiratory sleep disorders in idiopathic pulmonary fibrosis. Sleep Med Rev 2015; 26: 57-63.

142 Corte TJ, Wort SJ, Talbot S, et al. Elevated nocturnal desaturation index predicts mortality in interstitial lung disease. Sarcoidosis Vasc Diffuse Lung Dis 2012; 29: 41-50.

143 Mermigkis C, Bouloukaki I, Antoniou KM, et al. CPAP therapy in patients with idiopathic pulmonary fibrosis and obstructive sleep apnea: does it offer a better quality of life and sleep?. Sleep Breath 2013; 17: 1137-1143.

144 Pillai M, Olson AL, Huie TJ, et al. Obstructive sleep apnea does not promote esophageal reflux in fibrosing interstitial lung disease. Respir Med 2012; 106: 1033-1039.

145 Kohler M, Bloch KE, Stradling JR. Pharmacological approaches to the treatment of obstructive sleep apnoea. Expert Opin Investig Drugs 2009; 18: 647-656.

146 Carley DW, Olopade C, Ruigt GS, et al. Efficacy of mirtazapine in obstructive sleep apnea syndrome. Sleep 2007; 30: $35-41$.

147 Chrousos GA, Kattah JC, Beck RW, et al. Side effects of glucocorticoid treatment. experience of the optic neuritis treatment trial. JAMA 1993; 269: 2110-2112.

148 Lozada F, Silverman S, Migliorati C. Adverse side effects associated with prednisone in the treatment of patients with oral inflammatory ulcerative diseases. J Am Dent Assoc 1984; 109: 269-270.

149 Ryerson CJ, Arean PA, Berkeley J, et al. Depression is a common and chronic comorbidity in patients with interstitial lung disease. Respirology 2012; 17: 525e32.

150 Ryerson CJ, Berkeley J, Carrieri-Kohlman VL, et al. Depression and functional status are strongly associated with dyspnea in interstitial lung disease. Chest 2011; 139: 609-616.

151 Akhtar AA, Ali MA, Smith RP. Depression in patients with idiopathic pulmonary fibrosis. Chron Respir Dis 2013; 10: 127-133.

152 Fernandez Perez ER, Daniels CE, Schroeder DR, et al. Incidence, prevalence, and clinical course of idiopathic pulmonary fibrosis: a population based study. Chest 2010; 137: 129e37.

153 De Vries J, Kessels BL, Drent M. Quality of life of idiopathic pulmonary fibrosis patients. Eur Respir J 2001; 17: 954-961.

154 Elfferich MD, De Vries J, Drent M. Type D or "distressed" personality in sarcoidosis and idiopathic pulmonary fibrosis. Sarcoidosis Vasc Diffuse Lung Dis 2011; 28: 65-71.

155 DiMatteo MR, Lepper HS, Croghan TW. Depression is a risk factor for noncompliance with medical treatment: meta-analysis of the effects of anxiety and depression on patient adherence. Arch Intern Med 2000; 160: 2101-2107.

156 Holland A, Fiore J Jr, Bell EC, et al. Dyspnoea and comorbidity contribute to anxiety and depression in interstitial lung disease. Respirology 2014; 19: 1215-1221.

157 Swigris JJ, Fairclough DL, Morrison M, et al. Benefits of pulmonary rehabilitation in idiopathic pulmonary fibrosis. Respir Care 2011; 56: 783-789. 